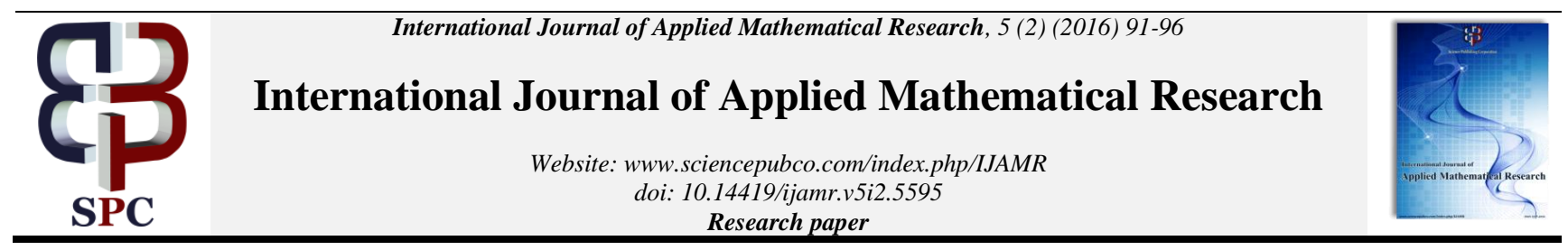

\title{
Fuzzy bicompletable quasi-fuzzy distance space
}

\author{
Jehad R. Kider *, Aisha J. Hassan \\ Department of Applied Mathematics and Computers, School of Applied Sciences, University of Technology \\ *Corresponding author E-mail: jehadkider@gmail.com
}

\begin{abstract}
In this paper we introduce the definition of quasi-fuzzy distance space then we discuss several properties of this space after we give an example to illustrate this notion. Then we show that the existence of a quasi-fuzzy distance space which is not fuzzy bicompletable. Here we prove that every fuzzy bicompletable quasi-fuzzy distance space admits a unique [up to fuzzy isodistance] fuzzy a bicompletion.
\end{abstract}

Keywords: Fuzzy Distance Space; Quasi-Fuzzy Distance Space; Fuzzy Bicompletable Quasi-Fuzzy Distance Space.

\section{Introduction}

Theory of fuzzy sets was introduced by Zadeh in 1965 [21]. Many authors have introduced the concept of fuzzy metric in Different ways [1], [2], [3], [7], [8], [9], [10], [13], [16], [17]. Kramosil and Michalek in 1975 [6] introduced the definition of fuzzy metric space which is called later KM-fuzzy metric space .George and Veeramani in 1994 [3] Introduced the definition of continuous $* \mathrm{t}$ norm to modify the concept of KM-fuzzy metric space which was introduced by Kramosil and Michalek which is called later GVfuzzy metric space. In section one of this paper we recall the definition of fuzzy distance space on fuzzy set [9] which is a modification of the definition GV-fuzzy metric space after that we introduce basic definitions ,basic concepts and properties of fuzzy distance space.

In section two of this paper we extend the notion fuzzy distance space on a fuzzy set to a quasi-fuzzy distance space on fuzzy set. On the other hand, it was presented in [4] an example of a fuzzy distance space that is not fuzzy completable, also it has been obtained an internal characterization of fuzzy completable fuzzy distance spaces, taking these results into account and the fact that the concept of fuzzy bicompletion provides a theory of completion to quasi-metric spaces in the classical sense (for instance see [5]). It seems natural and interesting to discuss the problem of characterizing quasi-fuzzy distance spaces that are fuzzy bicompletable. The main purpose of this paper is to solve this problem. Following the modern terminology ( for instance see Section 11 of [5] ) by a quasi-metric on a set $X$ we mean a function $d: X X \rightarrow[0, \infty)$ such that for all $\mathrm{x}, \mathrm{y}, \mathrm{z} \in \mathrm{X}$ :

i) $\quad d(x, y)=d(y, x)=0$ if and only if $x=y$

ii) $\quad d(x, y) \leq d(x, z)+d(z, y)$

Each quasi-metric $d$ on $X$ generates a $T_{0}$-topology $\tau_{d}$ which has a base the family of open balls $\left\{\mathrm{B}_{\varepsilon}(\mathrm{x}): \mathrm{x} \in \mathrm{X}, \varepsilon>0\right\}$ where $\mathrm{B}_{\varepsilon}(\mathrm{x})=\{\mathrm{y} \in \mathrm{X}: \mathrm{d}(\mathrm{x}, \mathrm{y})<\varepsilon\}$.

\section{Fuzzy distance space on fuzzy set}

Definition 2.1: [21] Let $X$ be a nonempty set of elements, a fuzzy set $\tilde{A}$ in $X$ is characterized by a membership function, $\mu_{\tilde{A}}(x): X \rightarrow$ $[0,1]$.

Then we can write $\widetilde{A}=\left\{\left(x, \mu_{\widetilde{A}}(x)\right): x \in X, 0 \leq \mu_{\widetilde{A}}(x) \leq 1\right\}$.

We now recall an example of a continuous fuzzy set.

Example 2.2: [18] Let $X=\mathbb{R}$ and let $\widetilde{A}$ be a fuzzy set in $\mathbb{R}$ with membership function by: $\mu_{\widetilde{A}}(x)=\frac{1}{1+10 x^{2}}$.

Definition 2.3: [4] Let $\tilde{A}$ and $\tilde{B}$ be two fuzzy sets in $X$. then

1) $\widetilde{\mathrm{A}} \subseteq \widetilde{\mathrm{B}}$ if and only if $\mu_{\tilde{\mathrm{A}}}(\mathrm{x}) \leq \mu_{\widetilde{\mathrm{B}}}(\mathrm{x})$ for all $\mathrm{x} \in \mathrm{X}$

2) $\widetilde{A}=\widetilde{B}$ if and only if $\mu_{\tilde{A}}(x)=\mu_{\widetilde{B}}(x)$ for all $x \in X$

3) $\tilde{C}=\widetilde{A} \cup \widetilde{B}$ if and only if $\mu_{\widetilde{C}}(x)=\mu_{\tilde{A}}(x) \vee \mu_{\widetilde{B}}(x)$ for all $x \in X$

4) $\widetilde{D}=\widetilde{A} \cap \widetilde{B}$ if and only if $\mu_{\widetilde{D}}(x)=\mu_{\tilde{A}}(x) \wedge \mu_{\widetilde{B}}(x)$ for all $x \in X$

5) $\mu_{\widetilde{\mathrm{A}}^{c}}(\mathrm{x})=1-\mu_{\tilde{\mathrm{A}}}(\mathrm{x})$ for all $\mathrm{x} \in \mathrm{X}$

Definition 2.4: [18] If $\tilde{A}$ and $\tilde{B}$ are fuzzy sets in a nonempty sets $X$ and $Y$ respectively then the Cartesian product $\tilde{A} \times \tilde{B}$ of $\tilde{A}$ and $\tilde{B}$ is defined by:

$\mu_{\tilde{\mathrm{A}} \times \widetilde{\mathrm{B}}}(\mathrm{x}, \mathrm{y})=\mu_{\tilde{\mathrm{A}}}(\mathrm{x}) \wedge \mu_{\widetilde{\mathrm{B}}}(\mathrm{y})$ for all $(\mathrm{x}, \mathrm{y}) \in \mathrm{X} \times \mathrm{Y}$

Definition 2.5: [20] A fuzzy point $p$ in $X$ is a fuzzy set with member $p(x)=\alpha$ if $x=y$ and $p(x)=0$ otherwise. For all $y$ in $X$ where $0<\alpha<1$. We denote this fuzzy point by $x_{\alpha}$. Two fuzzy points $x_{\alpha}$ and $y_{\beta}$ are said to be distinct if and only if $x \neq y$.

Definition 2.6: [21] Let $x_{\alpha}$ be a fuzzy point and $\tilde{A}$ be a fuzzy set in $X$. then $x_{\alpha}$ is said to be in $\tilde{A}$ or belongs to $\tilde{A}$ which is denoted by $x_{\alpha} \in \tilde{A}$ if and only if $\mu_{\tilde{\AA}}(x)>\alpha$.

Definition 2.7: [11] Let $f$ be a function from a nonempty set $X$ into a nonempty set $Y$. If $\tilde{B}$ is a fuzzy set in $Y$ then $f^{-1}(\tilde{B})$ is a fuzzy set 
in $X$ defined by: $\mu_{f^{-1}(\tilde{B})}(x)=\left(\mu_{\tilde{B} \mathrm{o}} f\right)(x)$ for all $x$ in $X$. Also if $\tilde{A}$ is a fuzzy set in $X$ then $f(\tilde{A})$ is a fuzzy set in $Y$ defined by:

$\mu_{\mathrm{f}(\tilde{\mathrm{A}})}(\mathrm{y})=\vee\left\{\mu_{\tilde{\mathrm{A}}}(\mathrm{x}): \mathrm{x} \in \mathrm{f}^{-1}(\mathrm{y})\right\}$, if $^{-1}(\mathrm{y}) \neq \varnothing$ and $\mu_{f(\tilde{\mathrm{A}})}(y)=0$, otherwise.

Proposition 2.8: [12] Let $\mathrm{f}: \mathrm{X} \rightarrow \mathrm{Y}$ be a function. Then for a fuzzy point $\mathrm{x}_{\alpha}$ in $\mathrm{X}, \mathrm{f}\left(\mathrm{x}_{\alpha}\right)$ is a fuzzy point in $\mathrm{Y}$ and $\mathrm{f}\left(\mathrm{x}_{\alpha}\right)=(\mathrm{f}(\mathrm{x}))_{\alpha}$.

Definition 2.9: [3] A binary operation $*:[0,1] \times[0,1] \rightarrow[0,1]$ is a continuous $t$-norm if $*$ satisfies the following conditions:

1) $*$ is associative and commutative.

2) $*$ is continuous.

3) $\mathrm{a} * 1=\mathrm{a}$ for all $\mathrm{a} \in[0,1]$.

4) $\mathrm{a} * \mathrm{~b} \leq \mathrm{c} * \mathrm{~d}$ whenever $\mathrm{a} \leq \mathrm{c}$ and $\mathrm{b} \leq \mathrm{d}$ where $\mathrm{a}, \mathrm{b}, \mathrm{c}, \mathrm{d} \in[0,1]$.

Remark 2.10: [3] For any $a>b$ we can find $c$ such that $a * c \geq b$ and for any $d$ we can find an e such that $e * e \geq d$ where $a, b, c, d, e$ $\in(0,1)$. We introduce the following definition.

Definition 2.11: [14] A triple $(\tilde{A}, \widetilde{D}, *)$ is said to be fuzzy distance space if $\tilde{A}$ is a fuzzy set of the nonempty set $X, *$ is a continuous $t$ norm and $\widetilde{D}$ is a fuzzy set on $\widetilde{A}^{2}$ satisfying the following conditions:

$\left(\mathrm{FD}_{1}\right) \widetilde{\mathrm{D}}\left(\mathrm{x}_{\alpha}, \mathrm{y}_{\beta}\right)>0$ for all $\mathrm{x}_{\alpha}, \mathrm{y}_{\beta} \in \widetilde{\mathrm{A}}$

$\left(\mathrm{FD}_{2}\right) \widetilde{\mathrm{D}}\left(\mathrm{x}_{\alpha}, \mathrm{y}_{\beta}\right)=1$ if and only if $\mathrm{x}_{\alpha}=\mathrm{y}_{\beta}$

$\left(\mathrm{FD}_{3}\right) \widetilde{\mathrm{D}}\left(\mathrm{x}_{\alpha}, \mathrm{y}_{\beta}\right)=\widetilde{\mathrm{D}}\left(\mathrm{y}_{\beta}, \mathrm{x}_{\alpha}\right)$ for all $\mathrm{x}_{\alpha}, \mathrm{y}_{\beta} \in \widetilde{\mathrm{A}}$

$\left(\mathrm{FD}_{4}\right) \widetilde{\mathrm{D}}\left(\mathrm{x}_{\alpha}, \mathrm{z}_{\sigma}\right) \geq \widetilde{\mathrm{D}}\left(\mathrm{x}_{\alpha}, \mathrm{y}_{\beta}\right) * \widetilde{\mathrm{D}}\left(\mathrm{y}_{\beta}, \mathrm{z}_{\sigma}\right)$ for all $\mathrm{x}_{\alpha}, \mathrm{y}_{\beta}$ and $\mathrm{z}_{\sigma} \in \widetilde{\mathrm{A}}$

$\left(\mathrm{FD}_{5}\right) \widetilde{\mathrm{D}}\left(\mathrm{x}_{\alpha}, \mathrm{y}_{\beta}\right)$ is a continuous fuzzy set

Example 2.12: [14] Let $X=\mathbb{N}$, and let $\widetilde{A}$ be a fuzzy set in $X$. Suppose that $a * b=a . b$ for all $a, b \in[0,1]$. Define $\widetilde{D}\left(x_{\alpha}, y_{\beta}\right)=\frac{x}{y}$ If $x \leq y$ and $\widetilde{D}\left(x_{\alpha}, y_{\beta}\right)=\frac{y}{x}$ If $y \leq x$, for all $x, y \in \mathbb{N}$.Then $(\widetilde{A}, \widetilde{D}, *)$ is a fuzzy distance space.

Example 2.13: [14] Let $X=\mathbb{R}$ and let $\widetilde{A}$ be a fuzzy set in $X$. Suppose that $\mathrm{a} * \mathrm{~b}=\mathrm{a}$.b for all $\mathrm{a}, \mathrm{b} \in[0,1]$. Define $\widetilde{\mathrm{D}}\left(\mathrm{x}_{\alpha}, \mathrm{y}_{\beta}\right)=\frac{1}{\mathrm{e}^{\left|\mathrm{x}_{\alpha}-\mathrm{y}_{\beta}\right|}}$ for all $\mathrm{x}_{\alpha}, \mathrm{y}_{\beta} \in \widetilde{\mathrm{A}}$. Then $(\widetilde{\mathrm{A}}, \widetilde{\mathrm{D}}, *)$ is a fuzzy distance space.

Definition 2.14: [14] Let $(\tilde{A}, \widetilde{D}, *)$ be a fuzzy distance space then $\widetilde{D}$ is continuous fuzzy set if whenever $\left(x_{n}, \alpha_{n}\right) \rightarrow x_{\alpha}$ and $\left(y_{n}, \beta_{n}\right) \rightarrow y_{\beta}$ in $\tilde{A}$ then $\widetilde{D}\left(\left(x_{n}, \alpha_{n}\right),\left(y_{n}, \beta_{n}\right)\right) \rightarrow \widetilde{D}\left(x_{\alpha}, y_{\beta}\right)$ that is $\lim _{n \rightarrow \infty} \widetilde{D}\left(\left(x_{n}, \alpha_{n}\right),\left(y_{n}, \beta_{n}\right)\right)=\widetilde{D}\left(x_{\alpha}, y_{\beta}\right)$.

Lemma 2.15: [14] Suppose that $(X, d)$ is an ordinary metric space and assume that $\tilde{A}$ is a fuzzy set in X. Define $d\left(x_{\alpha}, y_{\beta}\right)=d(x, y)$ for all $x_{\alpha}, y_{\beta} \in \tilde{A}$. Then $(\tilde{A}, d)$ is a metric space.

Example 2.16: [14] Let $X=\mathbb{R}$ and let $\widetilde{A}=[2, \infty]$ be a fuzzy set in $X$. Consider the mapping $\widetilde{\mathrm{D}}: \widetilde{\mathrm{A}} \times \widetilde{\mathrm{A}} \rightarrow[0,1]$ defined by $: \widetilde{\mathrm{D}}\left(\mathrm{a}_{\alpha}, \mathrm{b}_{\beta}\right)=1$ if $\mathrm{a}=\mathrm{b}$ and $\widetilde{\mathrm{D}}\left(\mathrm{a}_{\alpha}, \mathrm{b}_{\beta}\right)=\left(\frac{1}{\mathrm{a}}\right) \cdot \alpha+\left(\frac{1}{\mathrm{~b}}\right) \cdot \beta$

if $\mathrm{a} \neq \mathrm{b}$, where $\alpha * \beta=\alpha$. $\beta$ for all $\alpha, \beta \in[0,1]$

$\left(\mathrm{FM}_{4}\right)$ We show that $\widetilde{\mathrm{D}}\left(\mathrm{a}_{\alpha}, \mathrm{c}_{\sigma}\right) \geq \widetilde{\mathrm{D}}\left(\mathrm{a}_{\alpha}, \mathrm{b}_{\beta}\right) * \widetilde{\mathrm{D}}\left(\mathrm{b}_{\beta}, \mathrm{c}_{\sigma}\right)$ is not satisfied for all $\mathrm{a}_{\alpha}, \mathrm{b}_{\beta}, \mathrm{c}_{\sigma} \in \widetilde{\mathrm{A}}$. Let $\mathrm{a}=10, \mathrm{~b}=3$ and $\mathrm{c}=100$ where $\alpha=\frac{1}{a}, \beta=\frac{1}{b}, \sigma=\frac{1}{c}$ Since $a \neq b \neq c$

Then $\widetilde{\mathrm{D}}\left(\mathrm{a}_{\alpha}, \mathrm{b}_{\beta}\right)=\left(\frac{1}{\mathrm{a}}\right) \cdot \alpha+\left(\frac{1}{\mathrm{~b}}\right) \cdot \beta=\frac{1}{\mathrm{a}^{2}}+\frac{1}{\mathrm{~b}^{2}}=\frac{1}{100}+\frac{1}{9}$ $=0.01+0.111=0.121$

And $\widetilde{D}\left(b_{\beta}, c_{\sigma}\right)=\left(\frac{1}{b}\right) \cdot \beta+\left(\frac{1}{c}\right) \cdot \sigma=\frac{1}{b^{2}}+\frac{1}{c^{2}}=\frac{1}{9}+\frac{1}{10000}$ $=0.111+0.0001=0.1112$

$\widetilde{D}\left(a_{\alpha}, c_{\sigma}\right)=\left(\frac{1}{a}\right) \cdot \alpha+\left(\frac{1}{c}\right) \cdot \sigma=\frac{1}{a^{2}}+\frac{1}{c^{2}}=\frac{1}{100}+\frac{1}{10000}=0.01+0.0001=$ 0.0101

Therefore $\widetilde{D}\left(a_{\alpha}, b_{\beta}\right) * \widetilde{D}\left(b_{\beta}, c_{\sigma}\right)>\widetilde{D}\left(a_{\alpha}, c_{\sigma}\right)=(0.121)+$ $(0.1112)=0.0134552>0.0101$
Thus $(\tilde{A}, \widetilde{D}, *)$ is not a fuzzy distance space

Proposition 2.17: [14] Suppose that (X,d) is an ordinary metric space and assume that $\mathrm{a} * \mathrm{~b}=\mathrm{a} . \mathrm{b}$ for all $\mathrm{a}, \mathrm{b} \in[0,1]$. Then by lemma $2.15,(\tilde{A}, \mathrm{~d})$ is a metric space. Define $\widetilde{D}_{d}\left(x_{\alpha}, y_{\beta}\right)=\frac{t}{t+d\left(x_{\alpha}, y_{\beta}\right)}$, then $\left(\tilde{A}, \widetilde{D}_{d}, *\right)$ is a fuzzy distance space and it is called the fuzzy distance on the fuzzy set $\tilde{A}$ induced by d.

Definition 2.18: [14] Let $(\tilde{A}, \widetilde{D}, *)$ be a fuzzy distance space on the fuzzy set $\tilde{A}$, we define $\tilde{B}\left(x_{\alpha}, r\right)=\left\{y_{\beta} \in \tilde{A}: \widetilde{D}\left(x_{\alpha}, y_{\beta}\right)>(1-r)\right\}$ then $\tilde{B}\left(x_{\alpha}, r\right)$ is called an fuzzy open fuzzy ball with center the fuzzy point $x_{\alpha} \in \tilde{A}$ and radius $0<r<1$.

Proposition 2.19: [14] Suppose that $\tilde{B}\left(x_{\alpha}, r_{1}\right)$ and $\tilde{B}\left(x_{\alpha}, r_{2}\right)$ be two fuzzy open fuzzy balls with the same center $x_{\alpha} \in \tilde{\mathrm{A}}$ and with radiuses $r_{1}, r_{2} \in(0,1)$. Then we either have $\tilde{B}\left(x_{\alpha}, r_{1}\right) \subseteq \tilde{B}\left(x_{\alpha}, r_{2}\right)$ or $\tilde{B}\left(x_{\alpha}, r_{2}\right) \subseteq \tilde{B}\left(x_{\alpha}, r_{1}\right)$.

Definition 2.20: [14] A sequence $\left\{\left(x_{m}, \alpha_{m}\right)\right\}$ of fuzzy points in a fuzzy distance space $(\tilde{A}, \widetilde{D}, *)$ is called fuzzy converges to a fuzzy point $x_{\alpha} \in \tilde{A}$ if whenever $0<\varepsilon<1$, we can find a positive integer $K$ with, $\widetilde{D}\left(\left(x_{m}, \alpha_{m}\right), x_{\alpha}\right)>(1-\varepsilon)$ whenever $m \geq K$.

Definition 2.21: [14] A sequence $\left\{\left(x_{n}, \alpha_{n}\right)\right\}$ of fuzzy points in a fuzzy distance space $(\tilde{A}, \widetilde{D}, *)$ is called fuzzy converges to a fuzzy point $x_{\alpha} \in \tilde{A}$ if $\lim _{n \rightarrow \infty} \widetilde{D}\left(\left(x_{n}, \alpha_{n}\right), x_{\alpha}\right)=1$.

Theorem 2.22: [14] Definition 2.21 and definition 2.20 are equivalent.

Proposition 2.23: [14] Suppose that (X, d) is a metric space and assume that $\left(\tilde{A}, \widetilde{D}_{d}, *\right)$ is the fuzzy distance space induced by $\mathrm{d}$. $\operatorname{Let}\left\{\left(x_{n}, \alpha_{n}\right)\right\}$ be a sequence of fuzzy points in $\widetilde{A}$. Then $\left\{\left(x_{n}, \alpha_{n}\right)\right\}$ converges to $x_{\alpha} \in \tilde{A}$ in $(\tilde{\mathrm{A}}, \mathrm{d})$ if and only if $\left\{\left(x_{n}, \alpha_{n}\right)\right\}$ fuzzy converges to $x_{\alpha}$ in $\left(\tilde{A}, \widetilde{D}_{d}, *\right)$.

Definition 2.24: [14] A fuzzy subset $\tilde{C}$ of a fuzzy distance space $(\tilde{A}, \widetilde{D}, *)$ is called fuzzy open if for each $x_{\alpha} \in \tilde{C}$ there is $\tilde{B}\left(x_{\alpha}, q\right) \subset$ $\tilde{C}$ with $0<q<1$. A fuzzy set $\tilde{E} \subseteq \tilde{A}$ is said to be fuzzy closed if its complement is fuzzy open that is $\tilde{E}^{c}=\tilde{A} \backslash \tilde{E}$ is fuzzy open.

Theorem 2.25: [14] If $\tilde{B}\left(x_{\alpha}, q\right)$ is fuzzy open fuzzy ball in a fuzzy distance space $(\tilde{A}, \widetilde{D}, *)$ on a fuzzy set $\tilde{A}$ then $\tilde{B}\left(x_{\alpha}, q\right)$ is a fuzzy open fuzzy set with $0<q<1$.

Definition 2.26: [14] Suppose that $(\tilde{A}, \widetilde{D}, *)$ is a fuzzy distance space on a fuzzy set $\tilde{A}$ and let $\tilde{C} \subset \tilde{A}$ then the fuzzy closure of $\tilde{C}$ is denoted by $\overline{\tilde{C}}$ or $F C L(\tilde{C})$ and is defined to be the smallest fuzzy closed fuzzy set contains $\tilde{C}$.

Definition 2.27: [14] A fuzzy subset $\tilde{C}$ of a fuzzy distance space $(\tilde{A}, \widetilde{D}, *)$ on a fuzzy set $\tilde{A}$ is said to be fuzzy dense in $\tilde{A}$ if $\tilde{\tilde{C}}=\tilde{A}$.

Lemma 2.28: [14] Let $\tilde{C}$ be a fuzzy subset of $\tilde{A}$ and let $(\tilde{A}, \widetilde{D}, *)$ be a fuzzy distance space on the fuzzy set $\tilde{A}$ then $a_{\alpha} \in \overline{\tilde{C}}$ if and only if there is a sequence $\left\{\left(a_{n}, \alpha_{n}\right)\right\}$ in $\tilde{C}$ such that $\left(a_{n}, \alpha_{n}\right) \rightarrow a_{\alpha}$, where $\alpha, \alpha_{n} \in[0,1]$.

Theorem 2.29: [14] Suppose that $\tilde{C}$ is a fuzzy subset of a fuzzy distance space $\tilde{A}(, \widetilde{D}, *)$ then $\tilde{C}$ is fuzzy dense in $\tilde{A}$ if and only if for every $x_{\alpha} \in \tilde{A}$ there is $a_{\beta} \in \tilde{C}$ such that $\widetilde{D}\left(x_{\alpha}, a_{\beta}\right)>(1-\varepsilon)$ for some $0<\varepsilon<1$.

Definition 2.30: [14] A sequence $\left\{\left(x_{n}, \alpha_{n}\right)\right\}$ of fuzzy points in a fuzzy distance space $(\tilde{A}, \widetilde{D}, *)$ is said to be fuzzy Cauchy if whenever 01 we can find $K$ with $\widetilde{D}\left(\left(x_{n}, \alpha_{n}\right),\left(x_{m}, \alpha_{m}\right)\right)>(1-\varepsilon)$ for all $n$, $m \geq K$. 
Theorem 2.31: [14] Let ( $\tilde{A}, \widetilde{D}, *)$ be a fuzzy distance space on the fuzzy set $\tilde{A}$ if $\left\{\left(x_{n}, \alpha_{n}\right)\right\}$ is a sequence of fuzzy points in $\tilde{A}$ that is fuzzy converges to $x_{\alpha} \in \tilde{A}$ then $\left\{\left(x_{n}, \alpha_{n}\right)\right\}$ is fuzzy Cauchy.

Proposition 2.32: [14] Suppose that $(\mathrm{X}, \mathrm{d})$ is a metric space and let

$\widetilde{D}_{d}\left(x_{\alpha}, y_{\beta}\right)=\frac{t}{t+d\left(x_{\alpha}, y_{\beta}\right)}$ where $\mathrm{t}=\min \{\alpha, \beta\}$.

Then $\left\{\left(x_{n}, \alpha_{n}\right)\right\}$ is a Cauchy sequence in $(\tilde{A}, \mathrm{~d})$ if and only if $\left\{\left(x_{n}, \alpha_{n}\right)\right\}$ is a fuzzy Cauchy sequence in $\left(\tilde{A}, \widetilde{D}_{d}, *\right)$.

Definition 2.33: [14] Suppose that $(\tilde{A}, \widetilde{D}, *)$ be a fuzzy distance space. A fuzzy subset $\tilde{C}$ of $\tilde{A}$ is called fuzzy bounded if we can find $0<q<1$ with, $\widetilde{D}\left(x_{\alpha}, y_{\beta}\right)>(1-q)$, whenever $x_{\alpha}, y_{\beta} \in \tilde{C}$.

Proposition 1.34: [14] Let (X,d) be a metric space and let

$$
\widetilde{D}_{d}\left(x_{\alpha}, y_{\beta}\right)=\frac{t}{t+d\left(x_{\alpha}, y_{\beta}\right)}
$$

Where $\mathrm{t}=\alpha \wedge \beta$ then a fuzzy subset $\tilde{C}$ of $\tilde{\mathrm{A}}$ is fuzzy bounded if and only if it is bounded.

Definition 2.35: [14] Let $(\tilde{A}, \widetilde{D}, *)$ be a fuzzy distance space, then we define a fuzzy closed fuzzy ball with center $x_{\alpha} \in \tilde{A}$ and radius $r$, $0<r<1$ by $\tilde{B}\left[x_{\alpha}, r\right]=\left\{y_{\beta} \in X: \widetilde{D}\left(x_{\alpha}, y_{\beta}\right) \geq(1-r)\right\}$.

Lemma 2.36: [14] If $\tilde{B}\left[x_{\alpha}, q\right]$ is fuzzy closed fuzzy ball in a fuzzy distance space $(\tilde{A}, \widetilde{D}, *)$ on a fuzzy set $\tilde{A}$ then $\tilde{B}\left[x_{\alpha}, q\right]$ is a fuzzy closed fuzzy set with $0<q<1$.

Theorem 1.37: [14] Suppose that $(\tilde{A}, \widetilde{D}, *)$ is a fuzzy distance space. Put $\tau_{\widetilde{D}}=\left\{\tilde{C} \subset \tilde{A}: x_{\alpha} \in \tilde{C}\right.$ if and only if there is $0<q<1$ with $\left.\tilde{B}\left(x_{\alpha}, q\right) \subset \tilde{C}\right\}$.Then $\tau_{\widetilde{M}}$ is a fuzzy topology on $\tilde{A}$.

Proposition 2.38: [14] Suppose that (X,d) is an ordinary metric space. Let $\widetilde{D}_{d}\left(x_{\alpha}, y_{\beta}\right)=\frac{t}{t+d\left(x_{\alpha}, y_{\beta}\right)}$ be the fuzzy distance induced by $\mathrm{d}$. Then the topology $\tau_{d}$ induced by $\mathrm{d}$ and the fuzzy topology $\tau_{\widetilde{D}_{d}}$ induced by $\widetilde{D}_{d}$ are the same. That is $\tau_{d}=\tau_{\widetilde{D}_{d}}$.

Theorem 2.39: [14] Every fuzzy distance space on a fuzzy set is a fuzzy Hausdorff space.

Definition 1.40: [14] Suppose that $\left(\tilde{A}, \widetilde{D}_{\tilde{A}}, *\right)$ and $\left(\widetilde{E}, \widetilde{D}_{\widetilde{E}}, *\right)$ are fuzzy distance spaces and $\tilde{C} \subseteq \tilde{A}$.

The mapping h: $\tilde{C} \rightarrow \tilde{E}$ is said to be fuzzy continuous at $a_{\beta} \in \tilde{C}$, if whenever $0<\varepsilon<1$, we can find $0<\delta<1$, with $\widetilde{D}_{\widetilde{E}}\left(\mathrm{~h}\left(x_{\alpha}\right), \mathrm{h}\left(a_{\beta}\right)\right)$ $>(1-\varepsilon)$ whenever $x_{\alpha} \in \tilde{C}$ and $\widetilde{D}_{\tilde{\mathrm{A}}}\left(x_{\alpha}, a_{\beta}\right)>(1-\delta)$. When $\mathrm{f}$ is fuzzy continuous at every fuzzy point of $\tilde{C}$, then it is called to be fuzzy continuous on $\tilde{C}$.

Theorem 2.41: [14] Let ( $\left.\tilde{A}, \widetilde{D}_{\tilde{A}}, *\right)$ and $\left(\widetilde{E}, \widetilde{D}_{\tilde{E}}, *\right)$ be fuzzy distance spaces and $\tilde{C} \subseteq \tilde{A}$. The mapping $h: \tilde{C} \rightarrow \tilde{E}$ is fuzzy continuous at $a_{\beta} \in \tilde{C}$ if and only if whenever a sequence of fuzzy points $\left\{\left(x_{n}, \alpha_{n}\right)\right\}$ in $\tilde{C}$ fuzzy converge to $a_{\beta}$, then sequence of fuzzy points $\{(h$ $\left.\left.\left(x_{n}, \alpha_{n}\right)\right)\right\}$ fuzzy converges to $h\left(a_{\beta}\right)$.

Proposition 242: [11] Let $\tilde{A}$ be a fuzzy set in $\mathrm{X}$ and let $\tilde{B}$ be a fuzzy set in Y. let f: $\tilde{A} \rightarrow \tilde{B}$ be a function and let $\tilde{C} \subseteq \tilde{A}$ and $\tilde{E} \subseteq$ $\tilde{B}$.Then $\mathrm{f}(\tilde{C}) \subseteq \tilde{E}$ if and only if $\tilde{C} \subseteq f^{-1}(\tilde{E})$.

Theorem 2.43: [14] A mapping $f: \tilde{A} \rightarrow \tilde{E}$ is fuzzy continuous on $\tilde{A}$ if and only if the inverse image of $\tilde{C}$ is fuzzy open in $\tilde{A}$ for all fuzzy open fuzzy subset $\tilde{C}$ of $\widetilde{E}$. Where $\tilde{A}$ and $\tilde{E}$ are fuzzy distance spaces.
Theorem 2.44: [14] A mapping $f: \tilde{A} \rightarrow \tilde{E}$ is fuzzy continuous on $\tilde{A}$ if and only if the inverse image of $\tilde{C}$ is fuzzy closed in $\tilde{A}$ for all fuzzy closed fuzzy subset $\tilde{C}$ of $\widetilde{E}$.

\section{Fuzzy quasi- fuzzy distance space}

Definition 3.1: The triple $(\tilde{A}, \widetilde{D}, *)$ is called a quasi-fuzzy distance space where $\tilde{A}$ is a nonempty fuzzy set, $*$ is a continuous t-norm and $\widetilde{D}$ is a fuzzy set on $\tilde{A} \times \tilde{A}$ satisfying the following conditions:

1) For all $x_{\alpha}, y_{\beta} \in \tilde{A}, \widetilde{D}\left(x_{\alpha}, y_{\beta}\right)>0$

2) $\widetilde{D}\left(x_{\alpha}, y_{\beta}\right)=\widetilde{D}\left(y_{\beta}, x_{\alpha}\right)=1$ if and only if $x_{\alpha}=y_{\beta}$

3) $\widetilde{D}\left(x_{\alpha}, y_{\beta}\right) * \widetilde{D}\left(y_{\beta}, z_{\sigma}\right) \leq \widetilde{D}\left(x_{\alpha}, z_{\sigma}\right)$ for all $x_{\alpha}, y_{\beta}, z_{\sigma} \in \tilde{A}$

4) $\widetilde{D}$ is a continuous fuzzy set.

Proposition 3.2: If $(\tilde{A}, \widetilde{D}, *)$ is a fuzzy quasi fuzzy distance space then define $\widetilde{D}^{-1}: \tilde{A} \times \tilde{A} \rightarrow[0,1]$ by: $\widetilde{D}^{-1}\left(x_{\alpha}, y_{\beta}\right)=\widetilde{D}\left(y_{\beta}, x_{\alpha}\right)$ for all $x_{\alpha}, y_{\beta} \in \tilde{A}$. then $\left(\tilde{A}, \widetilde{D}^{-1}, *\right)$ is a quasi fuzzy distance space. Proof:

1) $\widetilde{D}^{-1}\left(x_{\alpha}, y_{\beta}\right)>0$ since $\widetilde{D}\left(y_{\beta}, x_{\alpha}\right)>0$ for all $x_{\alpha}, y_{\beta} \in \tilde{A}$

2) (2) $\widetilde{D}^{-1}\left(x_{\alpha}, y_{\beta}\right)=1$ if and only if $\widetilde{D}\left(y_{\beta}, x_{\alpha}\right)=1=\widetilde{D}\left(x_{\alpha}, y_{\beta}\right)$

$$
\Leftrightarrow y_{\beta}=x_{\alpha}
$$

3) $\widetilde{D}^{-1}\left(x_{\alpha}, y_{\beta}\right) * D^{-1}\left(y_{\beta}, z_{\sigma}\right)=\widetilde{D}\left(y_{\beta}, x_{\alpha}\right) * \widetilde{D}\left(z_{\sigma}, y_{\beta}\right) \leq$ $\widetilde{D}\left(z_{\sigma}, y_{\beta}\right) * \widetilde{D}\left(y_{\beta}, x_{\alpha}\right) \leq \widetilde{D}\left(z_{\sigma}, x_{\alpha}\right)=\widetilde{D}^{-1}\left(x_{\alpha}, z_{\sigma}\right)$

4) $\widetilde{D}^{-1}$ is continuous since $\widetilde{M}$ is continuous.

Therefore $\left(\tilde{A}, \widetilde{D}^{-1}, *\right)$ is a quasi fuzzy distance space

Proposition 3.3: Let $(\tilde{A}, \widetilde{D}, *)$ be a quasi-fuzzy distance space. Define $\tilde{G}: \tilde{A} \times \tilde{A} \rightarrow[0,1]$ by $\tilde{G}\left(x_{\alpha}, y_{\beta}\right)=\widetilde{D}\left(x_{\alpha}, y_{\beta}\right) \wedge \widetilde{D}^{-1}\left(x_{\alpha}, y_{\beta}\right)$. Then $(\tilde{A}, \tilde{G}, *)$ is a fuzzy metric space. We shall refer to $(\tilde{A}, \tilde{G}, *)$ as the fuzzy distance induced by $(\tilde{A}, \widetilde{D}, *)$.

Proof: It is sufficient to show that $\tilde{G}\left(x_{\alpha}, y_{\beta}\right)=\tilde{G}\left(y_{\beta}, x_{\alpha}\right)$ for each $x_{\alpha}, y_{\beta} \in \tilde{A}$.If $\tilde{G}\left(x_{\alpha}, y_{\beta}\right)=\widetilde{D}\left(x_{\alpha}, y_{\beta}\right)$ then $\tilde{G}\left(y_{\beta}, x_{\alpha}\right)$ must equal to $\widetilde{D}^{-1}\left(y_{\beta}, x_{\alpha}\right)$ but $\widetilde{D}^{-1}\left(y_{\beta}, x_{\alpha}\right)=\widetilde{D}\left(x_{\alpha}, y_{\beta}\right)$ that is $\widetilde{G}\left(y_{\beta}, x_{\alpha}\right)=\widetilde{D}\left(x_{\alpha}\right.$, $\left.y_{\beta}\right)$. Hence $\tilde{G}\left(x_{\alpha}, y_{\beta}\right)=\tilde{G}\left(y_{\beta}, x_{\alpha}\right)$

Similarly if $\tilde{G}\left(x_{\alpha}, y_{\beta}\right)=\widetilde{D}^{-1}\left(x_{\alpha}, y_{\beta}\right)$ then $\tilde{G}\left(x_{\alpha}, y_{\beta}\right)=\tilde{G}\left(y_{\beta}, x_{\alpha}\right)$ Therefore $(\tilde{A}, \tilde{G}, *)$ is a fuzzy distance space

Proposition 2.4: Suppose that $(\tilde{A}, \widetilde{D}, *)$ is a quasi fuzzy distance space. Then $\tau_{\widetilde{D}}=\left\{\tilde{C} \subset \tilde{A}: a_{\alpha} \in \tilde{C} \Leftrightarrow \exists \mathrm{r}, 0<\mathrm{r}<1\right.$, such that $\tilde{B}\left(a_{\alpha}, \mathrm{r}\right)$ $\subset \tilde{C}\}$ is a topology on $\tilde{A}$.

Proof:The proof is similar to the proof of Theorem 2.37, hence is omitted.

Example 3.5: Let $(\tilde{A}, \mathrm{~d})$ be an ordinary quasi metric space and let $\widetilde{D}_{d}$ be the function defined on $\tilde{A} \times \tilde{A}$ to $[0,1]$ by: $\widetilde{D}_{d}\left(x_{\alpha}, y_{\beta}\right)$ $=\frac{t}{t+d\left(x_{\alpha}, y_{\beta}\right)}$, where $\mathrm{t}=\alpha \wedge \beta$. Then for each continuous $\mathrm{t}$-norm $*$, $\left(\tilde{A}, \widetilde{D}_{d}, *\right)$ is a quasi-fuzzy distance space, which is called the fuzzy quasi metric space induced by the quasi metric d. Furthermore, it is easy to check that

$\left(\widetilde{D}_{d}\right)^{-1}=\widetilde{D}_{d^{-1}}$ and $\widetilde{G}_{d}=\widetilde{D}_{d^{s}}$ where $d^{-1}\left(x_{\alpha}, y_{\beta}\right)=$

$\mathrm{d}\left(y_{\beta}, x_{\alpha}\right), d^{s}\left(x_{\alpha}, y_{\beta}\right)=\max \left\{\mathrm{d}\left(x_{\alpha}, y_{\beta}\right), d^{-1}\left(x_{\alpha}, y_{\beta}\right)\right\}$

$\tilde{G}_{d}\left(x_{\alpha}, y_{\beta}\right)=\widetilde{M}_{d}\left(x_{\alpha}, y_{\beta}\right) \wedge \widetilde{M}_{d}^{-1}\left(x_{\alpha}, y_{\beta}\right)[12]$

Definition 3.6: A quasi fuzzy distance space $(\tilde{A}, \widetilde{D}, *)$ is called fuzzy bicomplete if $(\tilde{A}, \tilde{G}, *)$ is a fuzzy complete fuzzy distance space.

Definition 3.7: Let $(\tilde{A}, \widetilde{D}, *)$ be a quasi-fuzzy distance space. A fuzzy bicompletion of $(\tilde{A}, \widetilde{D}, *)$ is a fuzzy bicomplete quasi fuzzy distance space $(\tilde{E}, \widetilde{N}, \star)$ such that $(\tilde{A}, \widetilde{D}, *)$ is fuzzy isodistance to a fuzzy dense fuzzy subset of $\tilde{E}$. 
Lemma 3.8: Let $(\tilde{A}, \widetilde{D}, *)$ be a quasi fuzzy distance space. Denote by $\tilde{S}$ the collection of all fuzzy Cauchy sequence of fuzzy points in $(\tilde{A}, \tilde{G}, *)$.

Define a relation $\sim$ on $\tilde{S}$ by $\left\{\left(x_{n}, \alpha_{n}\right)\right\} \sim\left\{\left(x_{n}^{\prime}, \alpha_{n}^{\prime}\right)\right\}$ if and only if $\underline{\lim } \tilde{G}\left(\left(x_{n}, \alpha_{n}\right),\left(x_{n}^{\prime}, \alpha_{n}^{\prime}\right)\right)=1$, where by $\underline{\lim } \tilde{G}\left(\left(x_{n}, \alpha_{n}\right),\left(x_{n}^{\prime}, \alpha_{n}^{\prime}\right)\right)$ we denote the lower fuzzy limit of the sequence of fuzzy points $\left(\tilde{G}\left(\left(x_{n}, \alpha_{n}\right),\left(x_{n}^{\prime}, \alpha_{n}^{\prime}\right)\right)\right)$

i.e $\underline{\lim } \tilde{G}\left(\left(x_{n}, \alpha_{n}\right),\left(x_{n}^{\prime}, \alpha_{n}^{\prime}\right)\right)=\sup _{k} i n f_{n \geq k} \tilde{G}\left(\left(x_{n}, \alpha_{n}\right),\left(x_{n}^{\prime}, \alpha_{n}^{\prime}\right)\right)$. Then $\sim$ is an equivalence relation on $\tilde{S}$

Proof:

1) $\sim$ is reflexive because $\tilde{G}\left(\left(x_{n}, \alpha_{n}\right),\left(x_{n}, \alpha_{n}\right)\right)=1$ for all $\mathrm{n} \in \mathrm{N}$ so $\left(x_{n}, \alpha_{n}\right) \sim\left(x_{n}, \alpha_{n}\right)$

2) If $\left(x_{n}, \alpha_{n}\right) \sim\left(y_{n}, \beta_{n}\right)$, it immediately follows that $\left(y_{n}, \beta_{n}\right) \sim\left(x_{n}, \alpha_{n}\right)$ because $\widetilde{G}\left(\left(x_{n}, \alpha_{n}\right), \quad\left(y_{n}, \beta_{n}\right)\right)=$ $\widetilde{G}\left(\left(y_{n}, \beta_{n}\right),\left(x_{n}, \alpha_{n}\right)\right)$ for all $n \in N$, So that $\lim \widetilde{G}\left(\left(y_{n}, \beta_{n}\right)\right.$, $\left.\left(x_{n}, \alpha_{n}\right)\right)=\lim \widetilde{G}\left(\left(x_{n}, \alpha_{n}\right),\left(y_{n}, \beta_{n}\right)\right)=1$

3) 3- is transitive, suppose that $\left(\mathrm{x}_{\mathrm{n}}, \alpha_{\mathrm{n}}\right) \sim\left(\mathrm{y}_{\mathrm{n}}, \beta_{\mathrm{n}}\right)$ and $\left(\mathrm{y}_{\mathrm{n}}, \beta_{\mathrm{n}}\right) \sim\left(\mathrm{z}_{\mathrm{n}}, \sigma_{\mathrm{n}}\right)$. We shall prove $\lim \widetilde{\mathrm{G}}\left(\left(\mathrm{x}_{\mathrm{n}}, \alpha_{\mathrm{n}}\right),\left(\mathrm{z}_{\mathrm{n}}, \sigma_{\mathrm{n}}\right)\right)$ $=1$. Since $\left(x_{n}, \alpha_{n}\right) \sim\left(y_{n}, \beta_{n}\right)$ then $\underline{\lim } \widetilde{G}\left(\left(x_{n}, \alpha_{n}\right),\left(y_{n}, \beta_{n}\right)\right)$ $=1$.

Also $\left(y_{n}, \beta_{n}\right) \sim\left(z_{n}, \sigma_{n}\right)$ so $\underline{\lim } \tilde{G}\left(\left(y_{n}, \beta_{n}\right),\left(z_{n}, \sigma_{n}\right)\right)=1$

for all $\mathrm{n} \in \mathrm{N}$.

Now $\tilde{G}\left(\left(x_{n}, \alpha_{n}\right),\left(z_{n}, \sigma_{n}\right)\right) \geq \tilde{G}\left(\left(x_{n}, \alpha_{n}\right),\left(y_{n}, \beta_{n}\right)\right) * \tilde{G}\left(\left(y_{n}, \beta_{n}\right)\right.$, $\left.\left(z_{n}, \sigma_{n}\right)\right) \underline{\lim } \tilde{G}\left(\left(x_{n}, \alpha_{n}\right),\left(z_{n}, \sigma_{n}\right)\right) \geq \underline{\lim } \tilde{G}\left(\left(x_{n}, \alpha_{n}\right),\left(y_{n}, \beta_{n}\right)\right)$

$* \underline{\lim } \tilde{G}\left(\left(y_{n}, \beta_{n}\right),\left(z_{n}, \sigma_{n}\right)\right)$ Hence $\underline{\lim } \tilde{G}\left(\left(x_{n}, \alpha_{n}\right),\left(z_{n}, \sigma_{n}\right)\right)=1$

Lemma 3.9: Define $\widetilde{D}_{\tilde{S}}\left(\left(x_{n}, \alpha_{n}\right),\left(y_{n}, \beta_{n}\right)\right)=\underline{\lim } \widetilde{D}\left(\left(x_{n}, \alpha_{n}\right)\right.$, $\left.\left(y_{n}, \beta_{n}\right)\right)$ for all $\left(\left(x_{n}, \alpha_{n}\right),\left(\left(y_{n}, \beta_{n}\right)\right) \in \tilde{S}\right.$ where $\widetilde{D}_{\tilde{S}}$ : $\tilde{S} \times \tilde{S} \rightarrow[0,1]$. Then $\widetilde{D}_{\tilde{S}}$ satisfies 1, 3 and 4 of Definition 3.1.

Proof:

1) $\widetilde{D}_{\tilde{s}}\left(\left(x_{n}, \alpha_{n}\right),\left(y_{n}, \beta_{n}\right)\right)>0$ because $\widetilde{D}\left(\left(x_{n}, \alpha_{n}\right),\left(y_{n}, \beta_{n}\right)\right)>0$ so, $\lim \widetilde{D}\left(\left(x_{n}, \alpha_{n}\right),\left(y_{n}, \beta_{n}\right)\right)>0$.

2) Let $\left(x_{n}, \alpha_{n}\right),\left(y_{n}, \beta_{n}\right),\left(z_{n}, \sigma_{n}\right) \in \widetilde{S}$ and put $\alpha=\widetilde{D}_{\tilde{s}}\left(\left(x_{n}, \alpha_{n}\right)\right.$, $\left.\left(\mathrm{y}_{\mathrm{n}}, \beta_{\mathrm{n}}\right)\right), \beta=\widetilde{\mathrm{D}}_{\tilde{\mathrm{s}}}\left(\left(\mathrm{y}_{\mathrm{n}}, \beta_{\mathrm{n}}\right),\left(\mathrm{z}_{\mathrm{n}}, \sigma_{\mathrm{n}}\right)\right)$ and $\gamma=$ $\widetilde{\mathrm{D}}_{\tilde{\mathrm{s}}}\left(\left(\mathrm{x}_{\mathrm{n}}, \alpha_{\mathrm{n}}\right),\left(\mathrm{z}_{\mathrm{n}}, \sigma_{\mathrm{n}}\right)\right)$. We shall show that $\alpha * \beta \leq \gamma$

If $\alpha=0$ or $\beta=0$ the conclusion is clear. Hence we suppose that $\alpha>0$ and $\beta>0$.

Choose an arbitrary $\varepsilon \in\left(0, \min \frac{\{\alpha, \beta\}}{2}\right)$. Then

$(\alpha-\varepsilon)<\widetilde{D}_{\tilde{s}}\left(\left(x_{n}, \alpha_{n}\right),\left(y_{n}, \beta_{n}\right)\right)$ and $(\beta-\varepsilon)<\widetilde{D}_{\tilde{s}}\left(\left(y_{n}, \beta_{n}\right),\left(z_{n}, \sigma_{n}\right)\right)$ Furthermore, there exists $N_{\varepsilon}$ such that for all $\mathrm{k} \geq N_{\varepsilon}$

$\widetilde{D}_{\tilde{s}}\left(\left(x_{n}, \alpha_{n}\right), \quad\left(y_{n}, \beta_{n}\right)\right)-\varepsilon<\widetilde{D}\left(\left(x_{k}, \alpha_{k}\right), \quad\left(y_{k}, \beta_{k}\right)\right)$. And $\widetilde{D}_{\tilde{s}}\left(\left(y_{n}, \beta_{n}\right),\left(z_{n}, \sigma_{n}\right)\right)-\varepsilon<\widetilde{D}\left(\left(y_{k}, \beta_{k}\right),\left(z_{k}, \sigma_{k}\right)\right)$.

Then $(\alpha-2 \varepsilon) *(\beta-2 \varepsilon) \leq\left[\widetilde{D}_{\tilde{s}}\left(\left(x_{n}, \alpha_{n}\right),\left(y_{n}, \beta_{n}\right)\right)-\varepsilon\right] *$ $\left.\left[\widetilde{D}_{\tilde{S}}\left(\left(y_{n}, \beta_{n}\right)\right),\left(z_{n}, \sigma_{n}\right)\right)-\varepsilon\right] \leq \widetilde{D}\left(\left(x_{k}, \alpha_{k}\right),\left(y_{k}, \beta_{k}\right)\right) * \widetilde{D}\left(\left(y_{k}, \beta_{k}\right)\right.$ $\left.\left(z_{k}, \sigma_{k}\right)\right) \leq \widetilde{D}\left(\left(x_{k}, \alpha_{k}\right),\left(z_{k}, \sigma_{k}\right)\right)$ for all $\mathrm{k} \geq N_{\varepsilon}$

Therefore $(\alpha-2 \varepsilon) *(\beta-2 \varepsilon) \leq i n f_{k \geq N_{\varepsilon}} \widetilde{\mathrm{D}}\left(\left(x_{k}, \alpha_{k}\right),\left(z_{k}, \sigma_{k}\right)\right) \leq$ $\lim \widetilde{D}\left(\left(x_{n}, \alpha_{n}\right),\left(z_{n}, \sigma_{n}\right)\right)=\gamma$ By continuity of $*$, it follows that $\alpha * \beta \leq \gamma$

3) $\widetilde{\mathrm{D}}_{\widetilde{\mathrm{s}}}$ is continuous because $\widetilde{\mathrm{D}}$ is continuous

Notation 3.10: We denote the quotient $\tilde{S} / \sim$ by $\tilde{X}$ and $\left[\left(x_{n}, \alpha_{n}\right)\right]$ the class of the element $\left(x_{n}, \alpha_{n}\right)$ of $\tilde{S}$.

Lemma 3.11: If $\left(x_{n}, \alpha_{n}\right) \sim\left(a_{n}, \gamma_{n}\right)$ and $\left.\left(y_{n}, \beta_{n}\right)\right) \sim\left(b_{n}, \sigma_{n}\right)$ Then $\widetilde{D}_{\tilde{s}}\left(\left(x_{n}, \alpha_{n}\right),\left(y_{n}, \beta_{n}\right)\right)=\widetilde{D}_{\tilde{s}}\left(\left(a_{n}, \gamma_{n}\right),\left(b_{n}, \sigma_{n}\right)\right)$.

Proof: $\widetilde{D}_{\tilde{s}}\left(\left(x_{n}, \alpha_{n}\right),\left(y_{n}, \beta_{n}\right)\right) \geq \widetilde{D}_{\tilde{s}}\left(\left(x_{n}, \alpha_{n}\right),\left(a_{n}, \gamma_{n}\right)\right)$

$* \widetilde{D}_{\tilde{S}}\left(\left(a_{n}, \gamma_{n}\right),\left(b_{n}, \sigma_{n}\right)\right) * \widetilde{D}_{\tilde{S}}\left(\left(b_{n}, \sigma_{n}\right),\left(\left(y_{n}, \beta_{n}\right)\right)=\widetilde{D}_{\tilde{S}}\left(\left(a_{n}, \gamma_{n}\right)\right.\right.$, $\left.\left(b_{n}, \sigma_{n}\right)\right)$

Thus $\left.\widetilde{M}_{\tilde{S}}\left(\left(x_{n}, \alpha_{n}\right)\right),\left(y_{n}, \beta_{n}\right)\right) \geq \widetilde{M}_{\tilde{S}}\left(\left(a_{n}, \gamma_{n}\right),\left(b_{n}, \sigma_{n}\right)\right)$.

Now

$\widetilde{D}_{\tilde{s}}\left(\left(a_{n}, \gamma_{n}\right),\left(b_{n}, \sigma_{n}\right)\right) \geq \widetilde{D}_{\tilde{S}}\left(\left(a_{n}, \gamma_{n}\right),\left(\left(x_{n}, \alpha_{n}\right)\right) * \widetilde{D}_{\tilde{S}}\left(\left(x_{n}, \alpha_{n}\right)\right.\right.$,

$\left.\left(y_{n}, \beta_{n}\right)\right) * \widetilde{D}_{\tilde{S}}\left(\left(y_{n}, \beta_{n}\right),\left(b_{n}, \sigma_{n}\right)\right)=\widetilde{D}_{\tilde{s}}\left(\left(x_{n}, \alpha_{n}\right)\right),\left(\left(y_{n}, \beta_{n}\right)\right)$
So, $\widetilde{D}_{\tilde{s}}\left(\left(a_{n}, \gamma_{n}\right),\left(b_{n}, \sigma_{n}\right)\right) \geq \widetilde{D}_{\tilde{S}}\left(\left(x_{n}, \alpha_{n}\right)\right),\left(\left(y_{n}, \beta_{n}\right)\right)$

Therefore $\left.\widetilde{D}_{\tilde{s}}\left(\left(x_{n}, \alpha_{n}\right)\right),\left(y_{n}, \beta_{n}\right)\right)=\widetilde{D}_{\tilde{s}}\left(\left(a_{n}, \gamma_{n}\right),\left(b_{n}, \sigma_{n}\right)\right)$

Definition 3.12: For each $\left[\left(x_{n}, \alpha_{n}\right)\right],\left[\left(y_{n}, \beta_{n}\right)\right] \in \tilde{X}$ define $\widetilde{N}\left(\left[\left(x_{n}, \alpha_{n}\right)\right],\left[\left(y_{n}, \beta_{n}\right)\right]\right)=\widetilde{D}_{\tilde{S}}\left(\left(x_{n}, \alpha_{n}\right)\right),\left(\left(y_{n}, \beta_{n}\right)\right)$. Then $\widetilde{N}$ is a function from $\tilde{X} \times \tilde{X}$ to $[0,1]$ and it is well defined by Lemma 2.11 .

Also we define $\mathrm{T}: \tilde{A} \rightarrow \tilde{X}$ such that for each $x_{\alpha} \in \tilde{A}, \mathrm{~T}\left(x_{\alpha}\right)$ is the class of constant sequence of fuzzy points $x_{\alpha}, x_{\alpha}$,

Now, from the above construction we obtain the main result in this section.

Theorem 3.13: Suppose that $(\tilde{A}, \widetilde{D}, *)$ is a fuzzy quasi- fuzzy distance space.

Then

a) $(\tilde{X}, \widetilde{N}, *)$ is a fuzzy quasi- fuzzy distance space

b) $\mathrm{T}(\tilde{A})$ is fuzzy dense in $(\tilde{X}, \widetilde{N}, *)$

c) $(\tilde{A}, \widetilde{D}, *)$ is fuzzy isodistance to $(\mathrm{T}(\tilde{A}), \widetilde{N}, *)$

d) $(\tilde{X}, \widetilde{N}, *)$ is fuzzy bicomplete

Proof (a): $\widetilde{N}$ satisfies conditions 1, 3 and 4 of Definition 3.1 as an immediate consequence of Lemma 3.9. Now, let $\left\{\left(x_{n}, \alpha_{n}\right)\right\}$, $\left\{\left(y_{n}, \beta_{n}\right)\right\} \in \tilde{S}$ such that $\widetilde{N}\left(\left[\left(\left(x_{n}, \alpha_{n}\right)\right],\left[\left(y_{n}, \beta_{n}\right)\right]\right)=1\right.$. If $\left(z_{n}, \sigma_{n}\right) \in\left[\left(y_{n}, \beta_{n}\right)\right]$ it follows that from Lemma 3.11 that $\widetilde{M}_{\tilde{s}}\left(\left(z_{n}, \sigma_{n}\right),\left(y_{n}, \beta_{n}\right)\right)=1$. The same argument shows that $\left(z_{n}, \sigma_{n}\right) \in\left[\left(x_{n}, \alpha_{n}\right)\right]$ implies that $\widetilde{M}_{\tilde{s}}\left(\left(z_{n}, \sigma_{n}\right),\left(x_{n}, \alpha_{n}\right)\right)=1$.

We conclude that $\widetilde{N}\left(\left[\left(x_{n}, \alpha_{n}\right)\right],\left[\left(y_{n}, \beta_{n}\right)\right]\right)=1$ if and only if $\left[\left(x_{n}, \alpha_{n}\right)\right]=\left[\left(y_{n}, \beta_{n}\right)\right]$. Hence $(\tilde{X}, \widetilde{N}, *)$ is a quasi- fuzzy distance space

Proof (b): Let $\left\{\left(x_{n}, \alpha_{n}\right)\right\} \in \tilde{S}$ and $0<\varepsilon<1$. Since $\left\{\left(x_{n}, \alpha_{n}\right)\right\}$ is fuzzy Cauchy sequence of fuzzy points in $(\tilde{A}, \widetilde{D}, *)$ then there is $N_{\varepsilon}$ such that $\widetilde{D}\left(\left(x_{k}, \alpha_{k}\right),\left(x_{N_{\varepsilon}}, \alpha_{N_{\varepsilon}}\right)\right)>\left(1-\frac{\varepsilon}{2}\right)$ for all $\mathrm{k} \geq N_{\varepsilon}$

Thus $\widetilde{N}\left(\left[\left(x_{n}, \alpha_{n}\right)\right], \mathrm{T}\left(x_{N_{\varepsilon^{\prime}}}, \alpha_{N_{\varepsilon}}\right)\right)=\widetilde{D}_{S}\left(\left(x_{n}, \alpha_{n}\right), \mathrm{T}\left(x_{N_{\varepsilon^{\prime}}}, \alpha_{N_{\varepsilon}}\right)\right)$

$=\sup _{n} \inf _{k>n} \widetilde{D}\left(\left(x_{k}, \alpha_{k}\right),\left(x_{N_{\varepsilon}}, \alpha_{N_{\varepsilon}}\right)\right)$

$\geq \inf _{k \geq N_{\varepsilon}} \widetilde{D}\left(\left(x_{k}, \alpha_{k}\right),\left(x_{N_{\varepsilon}}, \alpha_{N_{\varepsilon}}\right)\right)$

$\geq\left(1-\frac{\varepsilon}{2}\right)>(1-\varepsilon)$

We have shown that $\mathrm{T}(\tilde{A})$ is fuzzy dense in $(\tilde{X}, \widetilde{N}, *)$

Proof (c): This is almost obvious because for each $x_{\alpha}, y_{\beta} \in \tilde{A}$, we have $\widetilde{N}\left(\mathrm{~T} x_{\alpha}, \mathrm{T} y_{\beta}\right)=\widetilde{M}\left(x_{\alpha}, y_{\beta}\right)$

Proof (d): Let $\tilde{E}\left(\left[\left(x_{n}, \alpha_{n}\right)\right], \quad\left[\left(x_{n}, \alpha_{n}\right)\right]\right)=\min$ $\left\{\widetilde{N}\left(\left[\left(x_{n}, \alpha_{n}\right),\left[\left(x_{n}, \alpha_{n}\right)\right]\right), \widetilde{N}^{-1}\left(\left[\left(x_{n}, \alpha_{n}\right),\left[\left(x_{n}, \alpha_{n}\right)\right]\right)\right\}\right.\right.$.

Let $\left\{\left(\tilde{x}_{n}, \tilde{\alpha}_{n}\right)\right\}$ be a fuzzy Cauchy sequence in $(\tilde{X}, \tilde{E}, *)$, then there is an increasing sequence $\left(n_{k}\right)$ in N such that $\tilde{E}\left(\left(\tilde{x}_{n}, \tilde{\alpha}_{n}\right),\left(\tilde{x}_{m}, \tilde{\alpha}_{m}\right)\right)$ $>\left(1-2^{-k}\right)$ for all $\mathrm{n}, \mathrm{m} \geq n_{k}$. Since $\mathrm{T}(\tilde{A})$ is fuzzy dense in $(\tilde{X}, \tilde{E}, *)$ then for each $\mathrm{k} \in \mathrm{N}$ there is $\left(y_{k}, \beta_{k}\right) \in \tilde{A}$ such that $\tilde{E}\left(\left(\tilde{x}_{n_{k}}, \tilde{\alpha}_{n_{k}}\right), T\left(y_{k}, \beta_{k}\right)\right)>\left(1-2^{-k}\right)$ for all $\mathrm{k} \in \mathrm{N}$.

We show that $\left\{\left(y_{k}, \beta_{k}\right)\right\}$ is a fuzzy Cauchy sequence of fuzzy points in $(\tilde{A}, \tilde{G}, *)$. To this end, choose $0<\varepsilon<1$. Take $\mathrm{j} \in \mathrm{N}$ such that $\left(1-2^{-j}\right) *\left(1-2^{-j}\right) *\left(1-2^{-j}\right)>(1-\varepsilon)$.Then for each $\mathrm{k}, \mathrm{m} \geq \mathrm{j}$, we have

$\widetilde{D}\left(\left(y_{k}, \beta_{k}\right),\left(y_{m}, \beta_{m}\right)\right)=\widetilde{N}\left(T\left(y_{k}, \beta_{k}\right), \mathrm{T}\left(y_{m}, \beta_{m}\right)\right)\left(T\left(y_{k}, \beta_{k}\right)\right.$, $\left.\left(\tilde{x}_{n_{k}}, \tilde{\alpha}_{n_{k}}\right)\right) * \widetilde{N}\left(\left(\tilde{x}_{n_{k}}, \tilde{\alpha}_{n_{k}}\right),\left(\tilde{x}_{n_{m}}, \tilde{\alpha}_{n_{m}}\right)\right) * \widetilde{N}\left(\left(\tilde{x}_{n_{m}}, \tilde{\alpha}_{n_{m}}\right), \mathrm{T}\left(y_{m}, \beta_{m}\right)\right)$ $\geq\left(1-2^{-k}\right) *\left(1-2^{-(k \wedge m)}\right) *\left(1-2^{-m}\right) \geq\left(1-2^{-j}\right) *\left(1-2^{-j}\right) *(1-$ $\left.2^{-j}\right)>(1-\varepsilon)$

And consequently $\left\{\left(y_{k}, \beta_{k}\right)\right\}$ is a fuzzy Cauchy sequence of fuzzy points in $(\tilde{A}, \tilde{G}, *)$. Therefore $\widetilde{y}_{\beta} \in \tilde{X}$, where $\tilde{y}_{\beta}=\left[\left(y_{k}, \beta_{k}\right)\right]$. Finally, we prove that $\left(\tilde{x}_{n}, \tilde{\alpha}_{n}\right)$ fuzzy converges to $\tilde{y}_{\beta}$ in $(\tilde{X}, \widetilde{E}, *)$.

Indeed, as in part (c) choose $0<\varepsilon<1$. Take $\mathrm{j} \in \mathrm{N}$ such that $\left(1-\quad 2^{-j}\right) *\left(1-2^{-j}\right) *\left(1-2^{-j}\right)>(1-\varepsilon)$ Since $\left(y_{k}, \beta_{k}\right)$ is a fuzzy Cauchy sequence of fuzzy points in $(\tilde{X}, \tilde{E}, *)$, the proof of part (b) shows that there is $\mathrm{k} \geq \mathrm{j}$ such that $\tilde{E}\left(\tilde{y}_{\beta}, T\left(y_{k}, \beta_{k}\right)\right)>(1$ $2^{-j}$ ) Then for $\mathrm{n} \geq n_{k}$, we obtain $\tilde{E}\left(\tilde{y}_{\beta}, \tilde{x}_{n}\right) \geq \tilde{E}\left(\tilde{y}_{\beta}, T\left(y_{k}, \beta_{k}\right)\right) *$ 
$\tilde{E}\left(T\left(y_{k}, \beta_{k}\right),\left(\tilde{x}_{n_{k}}, \tilde{\alpha}_{n_{k}}\right)\right) * \tilde{E}\left(\left(\tilde{x}_{n_{k}}, \tilde{\alpha}_{n_{k}}\right),\left(\tilde{x}_{n}, \tilde{\alpha}_{n}\right)\right) \geq\left(1-2^{-j}\right) *(1-$ $\left.2^{-k}\right) *\left(1-2^{-k}\right) \geq\left(1-2^{-j}\right) *\left(1-2^{-j}\right) *\left(1-2^{-j}\right)>(1-\varepsilon)$

We conclude that $(\tilde{X}, \widetilde{N}, *)$ is fuzzy bicomplete

Definition 3.14: A quasi- fuzzy metric space $(\tilde{A}, \widetilde{M}, *)$ is called fuzzy bicompletable if it admits a fuzzy bicompletion.

Theorem 3.15: Suppose that ( $\left.\tilde{\mathrm{A}}, \widetilde{D}_{\tilde{\mathrm{A}}}, *\right)$ is a quasi-fuzzy distance space and let $\left(\widetilde{E}, \widetilde{D}_{\tilde{E}}, \star\right)$ be a fuzzy bicomplete quasi-fuzzy distance space. If there is a fuzzy isodistance mapping f from a fuzzy dense fuzzy subset $\tilde{C}$ of $\tilde{\mathrm{A}}$ to $\tilde{E}$ then $f$ has a unique extension $f^{*}: \tilde{\mathrm{A}} \rightarrow \tilde{E}$.

Proof: We consider any $x_{\alpha} \in \tilde{\mathrm{A}}$ but $\tilde{\mathrm{A}}=\overline{\tilde{C}}$ so $x_{\alpha} \in \overline{\tilde{C}}$ then there is a sequence $\left\{\left(x_{n}, \alpha_{n}\right)\right\}$ of fuzzy points in $\tilde{C}$ such that $\left\{\left(\mathrm{x}_{n}, \alpha_{n}\right)\right\}$ fuzzy converges to $x_{\alpha}$ by Lemma 2.28 .

Then $\left\{\left(x_{n}, \alpha_{n}\right)\right\}$ is fuzzy Cauchy. Since $\mathrm{f}$ is fuzzy isodistance $\{\mathrm{f}$ $\left.\left(\left(x_{n}, \alpha_{n}\right)\right)\right\}$ is fuzzy Cauchy in $\tilde{E}$ but $\tilde{E}$ is fuzzy complete hence there is $y_{\alpha} \in \tilde{E}$ such that $\left\{\mathrm{f}\left(x_{n}, \alpha_{n}\right)\right\}$ fuzzy converges to $y_{\alpha}$. Now we define $f^{*}\left(x_{\alpha}\right)=y_{\alpha}$.

We now show that this definition is independent of the particular choice of the sequence in $\tilde{C}$ converging to $x_{\alpha}$. Suppose that $\left\{\left(x_{n}, \alpha_{n}\right)\right\}$ in $\tilde{C}$ fuzzy converges to $x_{\alpha}$ and $\left\{\left(z_{n}, \sigma_{n}\right)\right\}$ in $\tilde{C}$ fuzzy converges to $x_{\alpha}$. Then $\left\{\left(v_{m}, \gamma_{m}\right)\right\}$ fuzzy converges to $x_{\alpha}$ where $\left\{\left(v_{m}, \gamma_{m}\right)\right\}=\left(\left(x_{1}, \alpha_{1}\right),\left(z_{1}, \sigma_{1}\right),\left(x_{2}, \alpha_{2}\right),\left(z_{2}, \sigma_{2}\right), \ldots\right)$.

Hence $\left\{\left(\mathrm{f}\left(v_{m}, \gamma_{m}\right)\right)\right\}$ fuzzy converges and the two subsequence $\left\{\left(\mathrm{f}\left(x_{n}, \alpha_{n}\right)\right)\right\}$ and $\left\{\left(\mathrm{f}\left(z_{n}, \sigma_{n}\right)\right)\right\}$ of $\left\{\left(\mathrm{f}\left(v_{m}, \gamma_{m}\right)\right)\right\}$ must have the same fuzzy limit. This prove $f^{*}$ is uniquely defined at every $x_{\alpha} \in \tilde{\mathrm{A}}$. Clearly $f^{*}\left(x_{\alpha}\right)=\mathrm{f}\left(x_{\alpha}\right)$ for every $x_{\alpha} \in \tilde{C}$ so that $f^{*}$ is an extension of $\mathrm{f}$

Theorem 3.16: Suppose that ( $\left.\tilde{\mathrm{A}}, \widetilde{D}_{\tilde{\mathrm{A}}}, *\right)$ is a fuzzy distance space and let $\left(\tilde{E}, \widetilde{D}_{\tilde{E}}, \star\right)$ be a fuzzy bicomplete quasi-fuzzy distance space. If $f$ is an fuzzy isodistance mapping from a fuzzy dense fuzzy subset $\tilde{C}$ of $\tilde{\mathrm{A}}$ to $\tilde{E}$ then the unique extension $f^{*}: \tilde{\mathrm{A}} \rightarrow \widetilde{E}$ is a fuzzy isodistance.

Proof: Let $x_{\alpha}, y_{\beta} \in \tilde{\mathrm{A}}$ then there exists two sequences $\left\{\left(x_{n}, \alpha_{n}\right)\right\}$ and $\left\{\left(y_{n}, \beta_{n}\right)\right\}$ of fuzzy points in $\tilde{C}$ such that $\left(x_{n}, \alpha_{n}\right) \rightarrow x_{\alpha}$ and $\left(y_{n}, \beta_{n}\right) \rightarrow y_{\beta}$. Choose an arbitrary $0<\varepsilon<1$. Now:

$\varepsilon+\widetilde{D}_{\tilde{\AA}}\left(x_{\alpha}, y_{\beta}\right)>\widetilde{D}_{\tilde{\AA}}\left(x_{\alpha}, y_{\beta}\right)$. Furthermore, it follows that $\left\{\left(x_{n}, \alpha_{n}\right)\right\}$ and $\left\{\left(y_{n}, \beta_{n}\right)\right\}$ are fuzzy Cauchy sequences in $\tilde{C}$ so $\left\{f^{*}\left(\left(x_{n}, \alpha_{n}\right)\right)\right\}$ and $\left\{f^{*}\left(\left(y_{n}, \beta_{n}\right)\right)\right\}$ are fuzzy Cauchy sequences in $\widetilde{E}$. But $\tilde{E}$ is fuzzy complete hence $\left\{f^{*}\left(\left(y_{n}, \beta_{n}\right)\right)\right\}$ fuzzy converges to $f^{*}\left(y_{\beta}\right)$ and $\left\{f^{*}\left(\left(x_{n}, \alpha_{n}\right)\right)\right\}$ fuzzy converges to $f^{*}\left(x_{\alpha}\right)$.

Then we can find $\mathrm{K}$ with $\widetilde{D}_{\tilde{\mathrm{A}}}\left(x_{\alpha},\left(x_{n}, \alpha_{n}\right)\right)>(1-\varepsilon)$, $\widetilde{D}_{\tilde{A}}\left(\left(y_{n}, \beta_{n}\right), y_{\beta}\right)>(1-\varepsilon) \widetilde{D}_{\tilde{E}}\left(f^{*}\left(\left(x_{n}, \alpha_{n}\right)\right), f^{*}\left(x_{\alpha}\right)\right)>(1-\varepsilon)$ and $\widetilde{D}_{\tilde{E}}\left(f^{*}\left(\left(y_{n}, \beta_{n}\right)\right), f^{*}\left(y_{\beta}\right)\right)>(1-\varepsilon)$ for all $\mathrm{n} \geq \mathrm{K}$. Thus we have $\varepsilon+$ $\widetilde{D}_{\tilde{\AA}}\left(x_{\alpha}, y_{\beta}\right)>\widetilde{D}_{\tilde{A}}\left(x_{\alpha}, y_{\beta}\right) \geq \widetilde{D}_{\tilde{A}}\left(x_{\alpha},\left(x_{n}, \alpha_{n}\right)\right)$ $* \widetilde{D}_{\tilde{\mathrm{A}}}\left(\left(x_{n}, \alpha_{n}\right),\left(y_{n}, \beta_{n}\right)\right) * \widetilde{D}_{\tilde{\mathrm{A}}}\left(\left(y_{n}, \beta_{n}\right), y_{\beta}\right) \geq(1-\varepsilon) *$ $\widetilde{D}_{\tilde{E}}\left(f^{*}\left(\left(x_{n}, \alpha_{n}\right)\right), f^{*}\left(\left(y_{n}, \beta_{n}\right)\right)\right) *(1-\varepsilon)$ But $\widetilde{D}_{\tilde{E}}\left(f^{*}\left(\left(x_{n}, \alpha_{n}\right)\right), f^{*}\left(\left(y_{n}, \beta_{n}\right)\right)\right) \geq \widetilde{D}_{\widetilde{E}}\left(f^{*}\left(\left(x_{n}, \alpha_{n}\right)\right), f^{*}(\mathrm{x})\right) \star$ $\widetilde{D}_{\tilde{E}}\left(f^{*}\left(x_{\alpha}\right), f^{*}\left(y_{\beta}\right)\right) \star \widetilde{D}_{\tilde{E}}\left(f^{*}\left(\left(y_{n}, \beta_{n}\right)\right), f^{*}\left(y_{\beta}\right)\right) \geq(1-\varepsilon) \star$ $\widetilde{D}_{\widetilde{E}}\left(f^{*}\left(x_{\alpha}\right), f^{*}\left(y_{\beta}\right)\right) \star(1-\varepsilon)$ for all $\mathrm{n} \geq \mathrm{K}$. Therefore $\varepsilon+\widetilde{D}_{\tilde{\mathrm{A}}}\left(x_{\alpha}, y_{\beta}\right)$ $>(1-\varepsilon) *\left[(1-\varepsilon) \star \widetilde{D}_{\widetilde{E}}\left(f^{*}\left(x_{\alpha}\right), f^{*}\left(y_{\beta}\right)\right) \star(1-\varepsilon)\right] *(1-\varepsilon)$

By fuzzy continuity of $*$ and $\star$ it follows that $\widetilde{D}_{\tilde{\mathrm{A}}}\left(x_{\alpha}, y_{\beta}\right) \geq$ $\widetilde{D}_{\widetilde{E}}\left(f^{*}\left(\mathrm{x}_{\alpha}\right), \mathrm{f}^{*}\left(\mathrm{y}_{\beta}\right)\right)$.

A similar argument shows that $\widetilde{\mathrm{D}}_{\widetilde{\mathrm{E}}}\left(\mathrm{f}^{*}\left(\mathrm{x}_{\alpha}\right), \mathrm{f}^{*}\left(\mathrm{y}_{\beta}\right)\right) \geq \widetilde{\mathrm{D}}_{\tilde{\mathrm{A}}}\left(\mathrm{x}_{\alpha}, \mathrm{y}_{\beta}\right)$ For all $\mathrm{x}_{\alpha}, \mathrm{y}_{\beta} \in \tilde{\mathrm{A}}$ We conclude that $\mathrm{f}^{*}$ is an fuzzy isodistance from $\left(\tilde{\mathrm{A}}, \widetilde{\mathrm{D}}_{\tilde{\mathrm{A}}}, *\right)$ to $\left(\widetilde{\mathrm{E}}, \widetilde{\mathrm{D}}_{\widetilde{\mathrm{E}}}, \star\right)$

Theorem 3.17: Every fuzzy bicompletable quasi- fuzzy distance space admits a unique [up to fuzzy isodistance] fuzzy bicompletion.

Proof: Let $\left(\widetilde{\mathrm{E}}, \widetilde{\mathrm{D}}_{1}, \star\right)$ and $\left(\widetilde{\mathrm{Z}}, \widetilde{\mathrm{D}}_{2}, \circ\right)$ be two fuzzy bicompletions of $(\tilde{\mathrm{A}}, \widetilde{\mathrm{D}}, *)$ then we will prove that $\left(\widetilde{\mathrm{E}}, \widetilde{\mathrm{D}}_{1}, \star\right)$ and $\left(\tilde{\mathrm{Z}}, \widetilde{\mathrm{D}}_{2}, \circ\right)$ are fuzzy isodistance. Since $\left(\widetilde{\mathrm{E}}, \widetilde{\mathrm{D}}_{1}, \star\right)$ is a fuzzy bicompletion of $(\tilde{\mathrm{A}}, \widetilde{\mathrm{D}}, *)$ then there is an fuzzy isodistance $\mathrm{f}$ from $(\tilde{\mathrm{A}}, \widetilde{\mathrm{D}}, *)$ to a fuzzy dense fuzzy subset of $\left(\widetilde{\mathrm{E}}, \widetilde{\mathrm{D}}_{1}, \star\right)$.

By Theorem 3.15 and Theorem $3.16 \mathrm{f}$ admits a unique extension $\mathrm{f}^{*}$ onto $\left(\widetilde{\mathrm{E}}, \widetilde{\mathrm{D}}_{1}, \star\right)$ which is also a fuzzy isodistance.

Similarly $\mathrm{f}$ is a fuzzy isodistance extension ( $\tilde{\mathrm{A}}, \widetilde{\mathrm{D}}, *$ ) onto $\left(\tilde{\mathrm{Z}}, \widetilde{\mathrm{D}}_{2},{ }^{\circ}\right)$.To prove that $\mathrm{f}^{*}$ and $\tilde{\mathrm{f}}$ are fuzzy isodistance it remains to see that $\mathrm{f}^{*}$ and $f$ are onto we will show that $\mathrm{f}^{*}$ is onto. Indeed given $y_{\alpha} \in \widetilde{E}$ there is a sequence $\left\{\left(x_{n}, \alpha_{n}\right)\right\}$ of fuzzy points in $\tilde{A}$ such that $\mathrm{f}^{*}\left(\mathrm{x}_{\mathrm{n}}, \alpha_{\mathrm{n}}\right) \rightarrow \mathrm{y}_{\alpha}$. Since $\mathrm{f}^{*}$ is an fuzzy isodistance $\left\{\left(\mathrm{x}_{\mathrm{n}}, \alpha_{\mathrm{n}}\right)\right\}$ is a fuzzy Cauchy sequence, so it fuzzy converges to some fuzzy point $\mathrm{x}_{\alpha} \in \tilde{\mathrm{A}}$. Consequently $\mathrm{f}^{*}\left(\mathrm{x}_{\alpha}\right)=\mathrm{y}_{\alpha}$. Similarly we can prove that $\mathrm{f}$ is onto.

Hence $f^{*}$ and $f$ are fuzzy isodistance.

Now $\left(\widetilde{\mathrm{E}}, \widetilde{\mathrm{D}}_{1}, \star\right)$ is fuzzy isodistance to $(\tilde{\mathrm{A}}, \widetilde{\mathrm{D}}, *)$ and $(\tilde{\mathrm{A}}, \widetilde{\mathrm{D}}, *)$ is fuzzy isodistance to $\left(\widetilde{\mathrm{Z}}, \widetilde{\mathrm{D}}_{2}, \circ\right)$. Hence $\left(\widetilde{\mathrm{E}}, \widetilde{\mathrm{D}}_{1}, \star\right)$ is fuzzy isodistance to $\left(\tilde{\mathrm{Z}}, \widetilde{\mathrm{D}}_{2}, \circ\right)$

\section{Conclusion}

In this paper we represented the definition of fuzzy quasi-fuzzy Distance space and we show that all properties of quasi-metric Space can be proved in fuzzy quasi fuzzy distance space.

\section{References}

[1] Company, C.F. Romaguera, S. and Tirado, P, (2011) "The Bicompletion of Fuzzy Quasi metric spaces", Fuzzy Sets and Systems, Vol.166, 56-64. http://dx.doi.org/10.1016/j.fss.2010.12.004.

[2] Dersanambika, K.S. and Aswathy, M.R., (2011) "Fixed point theorem in fuzzy metric spaces", Int.J. contemp Math. Sciences, Vol.6, No.22, 1079-1089.

[3] Dubbois, D. and Prade, H. (1980)" Fuzzy sets and systems, Theory and Application", Academic Press, Inc.

[4] Hassan, A.G., (2002)" Pseudo- Complete fuzzy locally convex algebras" Ph.D. thesis, AL-Mustansirya University, Baghdad.

[5] George, A. and Veeramani, P. (1994)"On some results in fuzzy metric spaces", Fuzzy Sets and Systems, Vol.64, 395-399. http://dx.doi.org/10.1016/0165-0114(94)90162-7.

[6] Gregori, V. and Romaguera, S., (2000) "Some properties of fuzzy metric spaces ", Fuzzy Sets and Systems, Vol.115, 485-489. http://dx.doi.org/10.1016/S0165-0114(98)00281-4.

[7] Gregori, V., Romaguera, S. and sapena ,A.,(2001)"Uniform continuity in fuzzy metric spaces" ,Rend. Ist. Mat. Univ. trieste suppl.2, Vol.32, 81-88

[8] Gregori, V. and Sapena, A. (2002)"On fixed point theorems in fuzzy metric spsces", Fuzzy Sets and Systems, Vol.125, 245-253. http://dx.doi.org/10.1016/S0165-0114(00)00088-9.

[9] Gregori, V., Romaguera, S. and Sapena,A.,(2005)"A characterization of bicomppletable fuzzy quasi metric spaces " , Fuzzy Sets

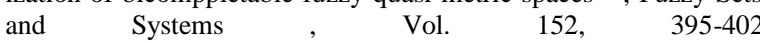
http://dx.doi.org/10.1016/j.fss.2004.09.006

[10] Gregori,V., Minana, J. and Morillas, S.(2012), "Some ques-tion in fuzzy metric spaces ", Fuzzy Sets and Systems Vol.204,71-85 http://dx.doi.org/10.1016/j.fss.2011.12.008.

[11] Hassan, A, J. (2015) "Properties of fuzzy distance on fuzzy set", M.Sc. Thesis, University of Technology, 2015.

[12] Klir, G. and Folger, T., (1988) "fuzzy sets Uncertainty and information ", prentice, Hall International, Inc.

[13] Kider, J. (2014),"Compact standard fuzzy metric space", International J. of Math. Archive, Vol .5 No.7, 129-136.

[14] Kider, J. R. and Hassan, A. J. (2015) "Properties of fuzzy distance on fuzzy set ", J. ofAdvances in mathematics, Vol.11, No.6, 52865299.

[15] Kramosil, D. and Michalek, J., (1975) "Fuzzy metric and statistical metric spaces, Kybernetika, Vol.11, 326-334.

[16] Lopez, R. and Romaguera, S., (2004)"The Hausdorff fuzzy metric on compact sets ", Fuzzy Sets and System, Vol.147, 273-283. http://dx.doi.org/10.1016/j.fss.2003.09.007.

[17] Mihet, D. (2004)"A Banach Contraction theorem in fuzzy metric spaces ", Fuzzy Sets and System Vol.144, 431-439. http://dx.doi.org/10.1016/S0165-0114(03)00305-1.

[18] Pao-Ming, P. and Ying-Ming, L, (1980) "Fuzzy Topology II, products and Quotient spaces", J. Math Anal. Appl.Vol.77, 20-37. http://dx.doi.org/10.1016/0022-247X(80)90258-9. 
[19] Rudin, W., (1974) "Functional Analysis". Tata Mcgraw - Hill publishing company ltd.

[20] Wong, C. (1974)"Fuzzy points and local properties of fuzzy Topology, J. Math Anal. Appl., Vol.46, 316-328 http://dx.doi.org/10.1016/0022-247X(74)90242-X.

[21] Zadeh, L (1965)."Fuzzy sets "Information and control, Vol.8, 338353. http://dx.doi.org/10.1016/S0019-9958(65)90241-X. 